\title{
\begin{tabular}{l|l} 
Mitraries & DSpace@MIT
\end{tabular}
}

\author{
MIT Open Access Articles
}

Condensation on Hydrophilic, Hydrophobic, Nanostructured Superhydrophobic and Oil-Infused Surfaces

The MIT Faculty has made this article openly available. Please share how this access benefits you. Your story matters.

Citation: Nenad, Miljkovic et al. "Condensation on Hydrophilic, Hydrophobic, Nanostructured Superhydrophobic and Oil-Infused Surfaces." Journal of Heat Transfer 135.8 (2013): 080906.

As Published: http://dx.doi.org/10.1115/1.4024188

Publisher: ASME International

Persistent URL: http://hdl.handle.net/1721.1/84996

Version: Author's final manuscript: final author's manuscript post peer review, without publisher's formatting or copy editing

Terms of use: Creative Commons Attribution-Noncommercial-Share Alike 

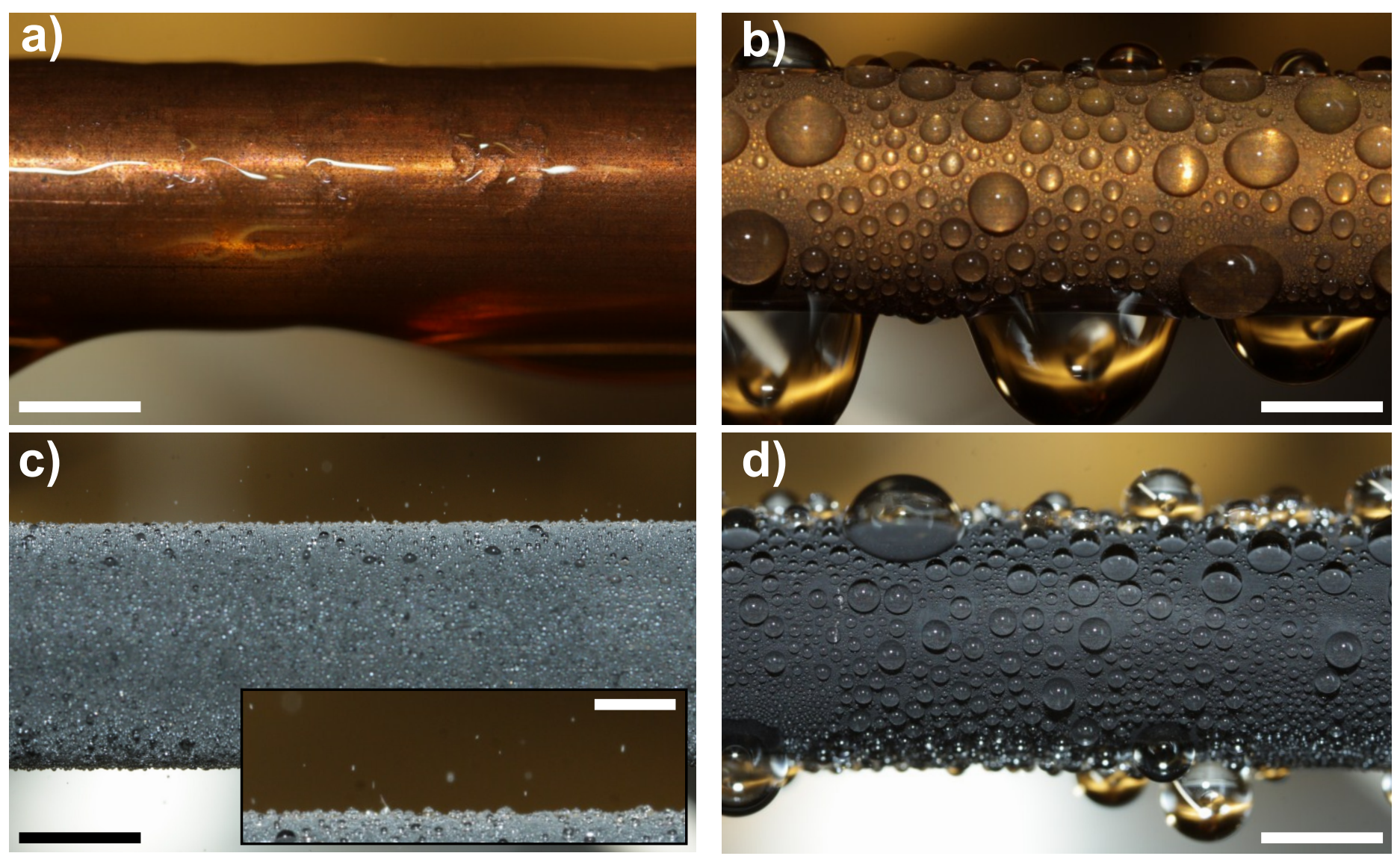

FIG 1. Images of (a) filmwise condensation on a smooth hydrophilic copper tube, (b) dropwise condensation on a silane coated smooth copper tube, (c) jumping-droplet superhydrophobic condensation on a nanostructured copper oxide tube (Inset: magnified view of the jumping phenomena, scale bar is $500 \mu \mathrm{m}$ ), and (d) immersion condensation on a nanostructured tube. Scale bars are $3 \mathrm{~mm}$. Vapor pressure $P_{\mathrm{v}} \approx 2700 \mathrm{~Pa}$.

a)

$\downarrow_{\text {antlow }}^{\substack{\text { Water } \\ \text { into }}}$

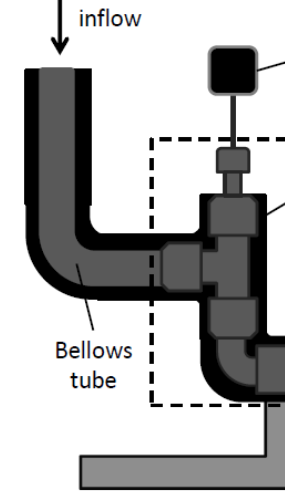

Thermocouple

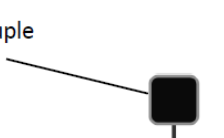

Water outflow

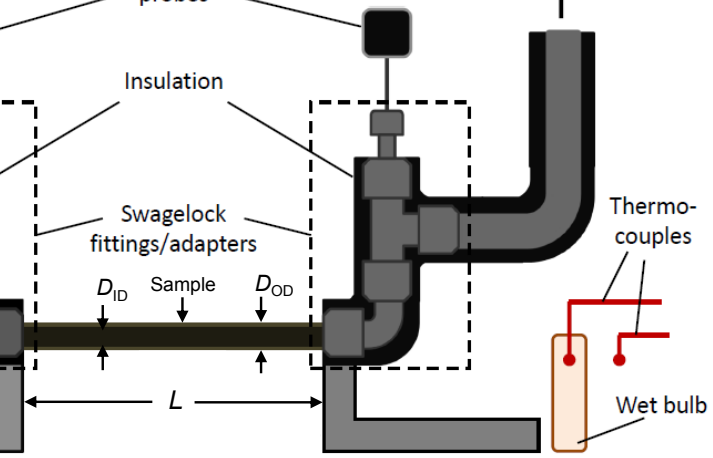

b)

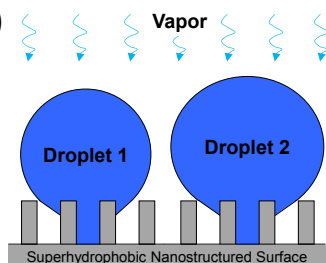

Pre Coalescence

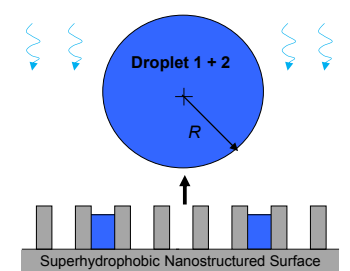

Post Coalescence c)

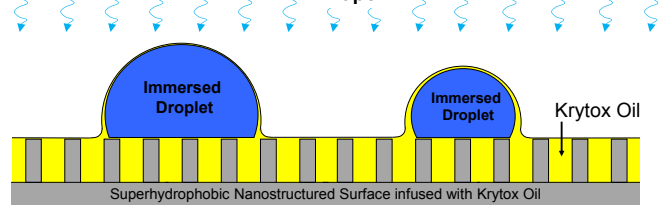

FIG 2. (a) Schematic showing experimental setup. The tube sample ( $\left.D_{\mathrm{OD}}=6.35 \mathrm{~mm}, D_{\mathrm{ID}}=3.56 \mathrm{~mm}, L=131 \mathrm{~mm}\right)$ was cooled via chilled water. Schematic showing (b) jumping-droplet condensation and (c) immersion condensation

\section{Condensation on Hydrophilic, Hydrophobic, Nanostructured Superhydrophobic and Oil-Infused Surfaces}

Nenad Miljkovic1, Rong Xiao ${ }^{1}$, Daniel John Preston ${ }^{1}$, Ryan Enright ${ }^{2}$, Ian McKay ${ }^{1}$ and Evelyn N. Wang1

1 Device Research Laboratory, Massachusetts Institute of Technology, Cambridge, MA, USA

${ }^{2}$ Thermal Management Research Group, Bell Labs Ireland, Alcatel-Lucent, Blanchardstown Business \& Technology Park, Dublin 15, Ireland

Color images of steady state water vapor condensing on smooth and nanostructured hydrophobic surfaces are presented. Figure 1a shows a snapshot of classical filmwise condensation on hydrophilic copper. A thin liquid film forms on the high surface energy substrate and acts as a conduction barrier for heat transfer. Figure 1b shows dropwise condensation on a copper tube made hydrophobic via deposition of a tri-chloro silane (TFTS). Discrete droplets form on the surface and, upon reaching a size comparable to the capillary length $(\approx 2.7 \mathrm{~mm})$, depart from the surface by gravitational sweeping. Figure 1c shows jumping-droplet condensation on a nanostructured superhydrophobic copper oxide (CuO) surface. When droplets coalesce on this surface, the resulting droplet can jump due to the release of excess surface energy (Figure $2 b$ ), and as a result, rapid droplet jumping is observed at micrometric length scales $(R<20 \mu \mathrm{m})$.
Figure 1d shows a novel mode of condensation called 'immersion' condensation, where nucleation density is drastically increased while maintaining easy condensate removal $(R<500 \mu \mathrm{m})$ and low contact angles $\left(<120^{\circ}\right)$. This approach utilizes an oil-infused nanostructured $\mathrm{CuO}$ surface with a heterogeneous coating which allows droplets to nucleate immersed within the oil (Figure 2c). The increase in nucleation density is achieved due to the combined effect of surface energy heterogeneity and a reduced oil-water interfacial energy. Figure 2a shows a schematic of the experimental setup. The visualizations provide insight into the complex droplet-surface interactions, which are important for the development of enhanced phase change surfaces. If designed properly, these surfaces not only allow for easy droplet removal at micrometric length scales during condensation but also promise to enhance heat transfer performance. 